\title{
Distinct Requirements for Evoked and Spontaneous Release of Neurotransmitter Are Revealed by Mutations in the Drosophila Gene neuronal-synaptobrevin
}

\author{
David L. Deitcher, ${ }^{1}$ Atsushi Ueda, ${ }^{2}$ Bryan A. Stewart, ${ }^{1}$ Robert W. Burgess, ${ }^{1}$ Yoshi Kidokoro, ${ }^{2}$ and \\ Thomas L. Schwarz ${ }^{1}$ \\ 1 Department of Molecular and Cellular Physiology, Beckman Center, Stanford University Medical Center, Stanford, \\ California 94305, and 'Gunma University School of Medicine, 3-39-22 Showa-machi, Maebashi, 371 Japan
}

Two modes of vesicular release of transmitter occur at a synapse: spontaneous release in the absence of a stimulus and evoked release that is triggered by $\mathrm{Ca}^{2+}$ influx. These modes often have been presumed to represent the same exocytotic apparatus functioning at different rates in different $\mathrm{Ca}^{2+}$ concentrations. To investigate the mechanism of transmitter release, we have examined the role of synaptobrevin/VAMP, a protein involved in vesicular docking and/or fusion. We generated a series of mutations, including null mutations, in neuronal-synaptobrevin ( $n$-syb), the neuronally expressed synaptobrevin gene in Drosophila. Mutant embryos completely lacking $n$-syb form morphologically normal neuromuscular junctions. Electrophysiological recordings from the neuromuscular junction of these mutants reveal that the excitatory synaptic current evoked by stimulation of the motor neuron is abolished entirely. However, spontaneous release of quanta from these terminals persists, although its rate is reduced by $75 \%$. Thus, at least a portion of the spontaneous "minis" that are seen at the synapse can be generated by a protein complex that is distinct from that required for an evoked synaptic response.

Key words: exocytosis; synaptobrevin; VAMP; Drosophila; synapse; neuromuscular junction; synaptic vesicle; spontaneous release; mini; regulated release
VAMP or synaptobrevin, syntaxin, and SNAP-25 bind to each other in vitro in a complex that is thought to be at the heart of vesicle docking and fusion (for review, see Jahn and Südhof, 1994). Support for their central role in exocytosis comes from the finding that homologs of these proteins are essential in many vesicular transport events within all eukaryotic cells (for review, see Calakos and Scheller, 1996).

In vertebrate synapses the importance of syntaxin, synaptobrevin, and SNAP-25 has been substantiated by studies with clostridial neurotoxins that block synaptic transmission by cleaving these proteins (for review, see Schiavo et al., 1994b). Synaptobrevin, in particular, is the target of tetanus toxin and botulinum toxins B, D, F, and G (Schiavo et al., 1992, 1994a; Yamasaki et al., 1994).

It has been hypothesized that the specificity of vesicle targeting to appropriate receptor membranes is dependent on a vesicle protein (v-SNARE) interacting specifically with the target membrane proteins (t-SNARE). Thus, the targeting of the synaptic vesicles to the active zone would be accomplished by VAMP/

\footnotetext{
Received June 30, 1997; revised Dec. 2, 1997; accepted Dec. 23, 1997.

This work was supported by a Silvio Conti Center for the Neurosciences award from the National Institute of Mental Health (T.L.S.); by a grant-in-aid from the Ministry of Education, Science, Sports, and Culture of Japan (Y.K.); and by fellowships from the Muscular Dystrophy Association (D.L.D.), American Heart Association (S.B.), Human Frontiers Program (B.A.S.), and the National Science Foundation and National Institutes of Health (R.W.B.). We thank Irene Inman for invaluable technical assistance and Huai Yu Mi for help in peptide coupling. We also thank Kendal Broadie for advice on dissections, Corey Goodman for the gift of monoclonal antibody 1D4 (anti-FasII), and Stephen DiNardo for the gift of Drosophila line 34.

Correspondence should be addressed to Dr. Thomas L. Schwarz, Beckman Center, Department of Molecular and Cellular Physiology, Stanford University Medical Center, Stanford, CA 94305-5426.

Dr. Deitcher's present address: Section of Neurobiology and Behavior, W125 Seeley Mudd Hall, Cornell University, Ithaca, NY 14853.

Copyright (c) 1998 Society for Neuroscience $0270-6474 / 98 / 182028-12 \$ 05.00 / 0$
}

synaptobrevin binding to syntaxin and SNAP-25 (Söllner et al., 1993; Calakos et al., 1994). However, the application of clostridial toxins that proteolyze these components has not been observed to alter the docking of vesicles at active zones in several electron microscopic studies (Hunt et al., 1994; Broadie et al., 1995).

Although the clostridial neurotoxin experiments have provided useful information, some caution is appropriate. The toxins may not cleave $100 \%$ of their target proteins, especially if the protein is complexed tightly with other proteins. Furthermore, clostridial toxins cleave their protein targets near their $\mathrm{C}$ termini, and it is unclear if the truncated proteins have residual function. The clostridial toxins also may have additional undefined proteolytic targets or have additional enzymatic activities (Ashton et al., 1995; Foran et al., 1996). A genetic approach sidesteps these problems.

Two synaptobrevin homologs have been described in Drosophila. One such homolog, synaptobrevin or syb (Südhof et al., 1989), is expressed most strongly in the gut (Chin et al., 1993), although it may be present in all tissues at a low level. Another homolog, neuronal-synaptobrevin ( $n$-syb), is highly expressed in the nervous system (DiAntonio et al., 1993a). $n$-syb is expressed in the embryonic CNS and PNS from $\sim 12 \mathrm{hr}$ after egg laying until adulthood; thus $n-s y b$ is an excellent candidate for a synaptic v-SNARE. Here we describe the generation of mutations in $n$-syb. Analysis of a null mutation has provided strong evidence that spontaneous fusions and evoked release differ in their requirements for this central component of the exocytotic complex.

\section{MATERIALS AND METHODS}

Cosmid screening, identification of $P 1$ clones, and preparation of probes. A cosmid library prepared from the isogenic strain Iso-1 (kindly provided by John Tamkun, University of California, Santa Cruz, CA) was plated 
on nylon membranes (Amersham, Arlington Heights, IL); the filters were processed by the standard Grunstein/Hogness method and hybridized with a cDNA probe, including the entire open reading frame (ORF) of $n$-syb in genomic hybridization buffer (Church and Gilbert, 1984). Seven positive clones were isolated, and one clone, 4D, was used for preparing probes for the P-element screen. Cosmid 4D was digested with a battery of enzymes, blotted, and hybridized with a cDNA probe as above. BamHI (New England Biolabs, Beverly, MA) digestion produced two hybridizing bands of 8 and $10 \mathrm{~kb}$. These fragments were subcloned into pBluescript SK ${ }^{+}$(Stratagene, La Jolla, CA). The resulting plasmids were BamHI-digested; the fragments were gel-purified twice and used as probes to identify pools from the P-element mutagenesis that contained a P-element insertion near $n$-syb. P1 clones from the area around $62 \mathrm{~A}$ and 62B were obtained from the Drosophila Genome Center at Stanford (Stanford, CA; kindly provided by Matthew Scott). These clones were digested with $B g l \mathrm{II}$ and $\mathrm{XhoI}$, separated by agarose gel electrophoresis, blotted, and probed with an $8 \mathrm{~kb}$ EcoRI genomic fragment from $n$-syb and the flanking DNA around the line 34 starter P-element (see Drosophila stocks below) to assess how far it was from the $n$-syb gene.

Drosophila stocks. Flies were grown at $22^{\circ} \mathrm{C}$ on standard cornmeal/ agar media. S. Dinardo (Rockefeller University, New York, NY) kindly provided line 34, which contains a single insertion of the plasmidrescuable P-element, $\mathrm{Plac} W$, at polytene band $62 \mathrm{~A} / \mathrm{B}$. The third chromosome of line 34 was made isozygotic after recombining away an unrelated third chromosome-lethal mutation with the third chromosome from a $y w$ stock. The transposase line containing the $\Delta 2-3$ source of transposase on the TMS balancer chromosome (marked with Stubble, $S b$ ) was provided by the Bloomington Drosophila Stock Center (Bloomington, IN).

P-element mutagenesis. Line 34 females were crossed to $w$; Dr/TMS, $\Delta 2-3, S b$ males and F1 $w+, S b$ males and females were selected. $750 \mathrm{~F} 1$ $w+, S b$ females and $700 \mathrm{~F} 1 w+, S b$ males (both with mottled eyes) were mated individually to $y w$ males and females, respectively. The F2 progeny were examined, and a single darker-eyed F2 male (that was not marked with $S b$ ) was selected from each vial. Approximately 900 darker-eyed F2 males were, in turn, mated individually to $y w$ females. After $5 \mathrm{~d}$, the males were retrieved from the vials and were pooled into groups of 30 for plasmid rescue.

Plasmid rescue. Thirty pools of 30 males were homogenized, and the genomic DNA from each pool was purified (Kaiser and Goodwin, 1990) and resuspended in $100 \mu \mathrm{l}$ of $10 \mathrm{~mm}$ Tris-Cl, $\mathrm{pH}$ 8.0, and $1 \mathrm{~mm}$ EDTA (TE) supplemented with $100 \mu \mathrm{g} / \mathrm{ml}$ RNase A (Sigma, St. Louis, MO). Ten microliters (three fly equivalents) were digested with $100 \mathrm{U}$ of EcoRI (New England Biolabs) for $2 \mathrm{hr}$ at $37^{\circ} \mathrm{C}$, phenol $/ \mathrm{CHCl}_{3}$-extracted, $\mathrm{CHCl}_{3}$-extracted, ethanol-precipitated, rinsed with $70 \%$ ethanol, and resuspended in $50 \mu \mathrm{l}$ of TE, $\mathrm{pH}$ 8.0. Each sample was ligated overnight at $18^{\circ} \mathrm{C}$ in a volume of $400 \mu \mathrm{l}$ (to promote intramolecular ligations) containing (in mM) 70 Tris- $\mathrm{Cl}, \mathrm{pH} 7.5,10 \mathrm{MgCl}_{2}, 1$ spermidine- $\mathrm{HCl}, 1$ ATP, and 10 DTT plus $90 \mu \mathrm{g} / \mathrm{ml}$ nuclease-free BSA (New England Biolabs) and $1200 \mathrm{U}$ of T4 DNA ligase (New England Biolabs). Ligation reactions were phenol $/ \mathrm{CHCl}_{3}$-extracted, $\mathrm{CHCl}_{3}$-extracted, ethanolprecipitated, rinsed with $70 \%$ ethanol three times, and resuspended in 10 $\mu \mathrm{l}$ of $\mathrm{H}_{2} 0$. The ligated DNA was added to $50 \mu \mathrm{l}$ of Electromax $\mathrm{DH} 10 B$ Escherichia coli (Life Technologies, Gaithersburg, MD) and electroporated with a Bio-Rad Genepulser (Bio-Rad, Hercules, CA). The bacteria were plated on $150 \mathrm{~mm} \mathrm{LB}$-agar plates supplemented with $100 \mu \mathrm{g} / \mathrm{ml}$ ampicillin and grown overnight. The 300-1000 colonies resulting from each pool were scraped off the plates; their DNA was purified, digested with EcoRI, electrophoresed on $0.8 \%$ agarose (Life Technologies) gels, transferred to nylon membranes (Amersham), and UV cross-linked (Stratagene). The blots were probed with two randomly primed ${ }^{32} \mathrm{P}$ labeled genomic Bam HI fragments $(8$ and $10 \mathrm{~kb})$ and hybridized as described for the P1 blots. Blots were exposed to XAR film (Kodak, Rochester, NY) for several hours with an intensifying screen, and the two pools showing significant hybridization were identified. The two positive pools were subdivided and screened as described above until two different individual lines were identified, F33 and F82. Balanced stocks were established for lines F33 and F82 over TM3, Sb or TM6, Ubx, $y+$ or $T M 6 B, H u, T b$.

F33, a homozygous-lethal mutation, contained a P-element insertion in exon 1 of $n$-syb $150 \mathrm{bp} 5^{\prime}$ of the initiation ATG (in addition to the original starter P-element of line 34), as determined by sequencing the rescued plasmid and by Southern blot analysis. The original line 34 insertion in the F33 line was recombined away from the $n$-syb insertion; that stock was used in subsequent experiments and will be referred to as $n-s y b^{\mathrm{F} 33-\mathrm{R}}$. The additional P-element insertion in F82 was $\sim 4$ kb downstream of the $n$-syb gene and was homozygous-viable; it apparently did not affect the transcription of the $n$-syb gene.

P-element excisions. $n$-syb ${ }^{\mathrm{F} 33-\mathrm{R}}$ and $n$-syb $b^{\mathrm{F} 82}$ females were mated to $w$; $D r / T M S, \Delta 2-3$, $S b$ males. $w^{+}$, $S b$ F1 males were mated to $w ; C X D / T M 3, S b$ virgin females. Approximately $700 w \mathrm{~F} 2$ males were selected and tested for lethality in combination with $n-s y b^{\mathrm{F} 33}$. Lines were established from lethal excisions $n$-syb $b^{\Delta \mathrm{F} 33 \mathrm{~B}}, n-s y b^{\Delta \mathrm{F} 33 \mathrm{OO}}, n$-syb ${ }^{\Delta \mathrm{F} 82 \mathrm{C}}$, and $n$-syb $b^{\Delta \mathrm{F} 33-8}$ over the balancers TM3, Sb, TM6, Ubx, $y+$ and $T M 6 B, H u, T b$. Seven excision lines that were viable in combination with $n-s y b^{\mathrm{F} 33}$ and were homozygous-viable for the excision chromosome also were established. Genomic DNA from the viable lines was digested with EcoRI, blotted, probed with the $2 \mathrm{~kb} E c o \mathrm{RI} n$-syb genomic fragment, and exposed to film as described above.

F2 lethal screen. An F2 lethal screen was performed to generate EMS alleles of $n$-syb. Briefly, isozygotic red ebony (red e) males were treated with EMS (ethane methyl sulfonate, Sigma) and mated to $w$; $C X D / T M 3$, $S b$ virgin females. The resulting F1 red $e * / T M 3, S b$ males were crossed to $n$-syb $b^{\mathrm{F} 33} / T M 3$, $S b$ virgins; vials were scored after $14 \mathrm{~d}$. Vials containing only $S b$ flies were selected. Two lines, I4 and I18, that initially showed lethality in the F2 lethal screen were identified. Subsequently, recrossing these lines to $n$-syb $b^{\mathrm{F} 33} / T M 3$ resulted in viable red $e^{* / n}$-syb ${ }^{\mathrm{F} 33}$ adult flies that were severely uncoordinated. Stocks were generated of the hypomorphic alleles of $n$-syb $b^{\mathrm{I} 4}$ and $n$-syb $b^{\mathrm{I} 18}$

PCR and Southern blot analysis of excisions. DNA was prepared from each of the $65 n$-syb $b^{\mathrm{F} 33-\mathrm{R}}$ excisions that failed to complement the $n$-syb ${ }^{\mathrm{F} 33-\mathrm{R}}$ P-element insertion, and these DNAs were used in a PCR assay with a primer to the $31 \mathrm{bp}$ repeat in the P-element (5'CGACGGGACCACCTTATGTTATTTCATCATG-3') and a downstream primer in exon 1 of $n$-syb (5'-GCACGATGCACTTGGCCTCTTTC- $3^{\prime}$ ) with the polymerase Tf (Epicentre Technologies, Madison, $\mathrm{WI}$ ). The amplification conditions included a denaturation temperature of $95^{\circ} \mathrm{C}$, an annealing temperature of $50^{\circ} \mathrm{C}$, and an extension temperature of $72^{\circ} \mathrm{C}$ (each for $1 \mathrm{~min}$ ) for 35 cycles, followed by a $10 \mathrm{~min}$ extension at $72^{\circ} \mathrm{C}$. Reaction products were electrophoresed on $3 \%$ agarose gels $(2 \%$ NuSieve GTG, FMC, and 1\% agarose; Life Technologies). The six $n$-syb ${ }^{\mathrm{F} 33}$ excision lines that did not produce a PCR product (indicating a deletion that either removed the $31 \mathrm{bp}$ repeat of the P-element or the sequence $3^{\prime}$ of the P-element insertion) were analyzed by Southern blotting, along with the F82 excisions and some 40 additional $n$-syb $b^{\mathrm{F} 33}$ excision lines. DNA was prepared as above and digested with EcoRI, Pst I, and XhoI (New England Biolabs) and in every double-digest combination and blotted as described. Southern blots were probed with a series of genomic probes that spanned the entire $n$-syb ORF and extended both $5^{\prime}$ and $3^{\prime}$ of the gene (see Fig. 2). Several excision lines were identified that deleted portions of the $n-s y b$ gene, including $n-s y b^{\Delta \mathrm{F} 33 \mathrm{~B}}$ $n$-syb ${ }^{\Delta \mathrm{F} 33 \mathrm{OO}}, n-s y b^{\Delta \mathrm{F} 82 \mathrm{C}}$, and $n-s y b^{\Delta \mathrm{F} 33-8}$.

Antibody preparation. Peptide NKLGLIGGEQPPQYQYPPQYM was synthesized at the Beckman Center Peptide and Nucleic Acid Facility (Stanford, CA). The peptide was coupled to thyroglobulin, using glutaraldehyde as described (Harlow and Lane, 1988), and used as an immunogen. Antisera were prepared, affinity-purified, and stored as described (Mi et al., 1995).

Western blots. Heads or bodies from wild-type and $n$-syb mutant lines were dissected and homogenized in $50 \mu \mathrm{l}$ of 5\% SDS, $0.2 \mathrm{M}$ Tris base, $10 \%$ glycerol, and $0.1 \%$ bromophenol blue and heated at $95^{\circ} \mathrm{C}$ for $4 \mathrm{~min}$. The samples were run on a $15 \%$ acrylamide gel and blotted onto Immobilon P (Millipore, Bedford, MA) membranes. Membranes were blocked in PBT (PBS plus $0.05 \%$ Tween 20) supplemented with 5\% nonfat dry milk. Blots were incubated with either a 1:500 (see Fig. 3B) or a 1:2000 (Fig. $3 A$ ) dilution of affinity-purified anti- $n$-syb antisera in PBT plus $1 \%$ BSA for $1 \mathrm{hr}$ at room temperature, washed extensively for $30 \mathrm{~min}$ in PBT, and then incubated with a 1:20,000-1:50,000 dilution of anti-rabbit-HRP conjugate (Amersham) in PBT plus 1\% BSA and washed as above. The blots were incubated with chemiluminescent substrate according the ECL kit directions (Amersham) and exposed to Biomax ML film (Kodak). Exposures ranged from $1 \mathrm{~min}$ to $1 \mathrm{hr}$, depending on the signal intensity.

Immunofluorescence. $y w ; n-s y b^{\Delta \mathrm{F} 33 \mathrm{~B}} / n-s y b^{\Delta \mathrm{F} 33 \mathrm{~B}}$ mutant embryos were collected from the stock $y w ; n-s y b^{\Delta \mathrm{F} 33 \mathrm{~B}} / T M 6 U b x, y+$ and $y w ; n-s y b^{\Delta \mathrm{F} 33 \mathrm{~B}} /$ TM6 Ubx, $y+$ siblings served as controls.

Embryos were collected on grape juice plates at $25^{\circ} \mathrm{C}$. The animals were hand-dechorionated and devitellinized. Late stage 17 embryos were affixed to SYLGARD-coated (Dow Corning, Midland, MI) slides with Nexaband (Veterinary Products Laboratories) glue. The glue was ap- 
plied in small drops from the end of a glass micropipette. The head and tail of the animal were glued down first before the dorsal midline of the animal was perforated with a sharp glass micropipette. Then an incision was made along the perforation, the animal was laid out along this incision, and the flaps of cuticle were glued to the slide. The gut, fat bodies, and connective tissue then were removed to expose the CNS and musculature. Dissections were performed in HL3 physiological solution, as described by Stewart et al. (1994).

The dissected preparations were fixed in Bouin's fixative (15:5:1 mixture of saturated picric acid, 37\% formaldehyde, and glacial acetic acid) for 15-30 min, washed in PBT (PBS plus $0.1 \%$ Triton X-100) for 30-60 min, blocked in $5 \%$ normal goat serum in PBT for $30 \mathrm{~min}$, and then incubated in affinity-purified rabbit anti- $n-s y b$ antiserum (1:250) and mouse anti-Fasciclin II monoclonal $(1: 50)$ overnight at $4^{\circ} \mathrm{C}$. The preparations were washed in PBT for 30-60 min, blocked in 5\% normal goat serum in PBT for $30 \mathrm{~min}$, incubated in FITC-conjugated goat anti-rabbit $(1: 250)$ and Texas Red-conjugated goat anti-mouse (1:250) (Jackson ImmmunoResearch Labs, West Grove, PA) for $2 \mathrm{hr}$ at room temperature, and then washed in PBT for 30-60 min. Mutant and control samples were dissected on the same slide.

The preparations were mounted in Vectashield (Vector Laboratories, Burlingame, CA) and viewed on a Molecular Dynamics (Sunnyvale, CA) confocal microscope. All images comparing mutant and wild-type animals were acquired at the same gain.

Electrophysiology. Embryos from the stock $y w ; n-s y b^{\Delta \mathrm{F} 33 \mathrm{~B}} / T M 6, U b x$, $y+$ and $y w ; n-s y b^{\mathrm{F} 33-\mathrm{R}} / \mathrm{TM} 6, U b x, y+$ and $y w$; line 34/TM6, Ubx, $y+$ were collected, and $y^{-} n$-syb homozygotes were identified. Dissecting and recording procedures of synaptic currents were described elsewhere (Kidokoro and Nishikawa, 1994; Nishikawa and Kidokoro, 1995). The dissecting procedures were performed in $\mathrm{Ca}^{2+}$-free, $\mathrm{Mg}^{2+}$ saline (see below). The ventral ganglion was kept intact. The preparation was treated for $3 \mathrm{~min}$ with $1 \mathrm{mg} / \mathrm{ml}$ collagenase (Type IV; Sigma) in $0.1 \mathrm{~mm}$ $\mathrm{Ca}^{2+}$ saline.

Recordings were mainly from longitudinal muscles 4, 6, and 7. The miniature synaptic current frequency was counted visually for $5 \mathrm{~min}$ on a CRT screen with simultaneous recording on a paper recorder (NihonKohden, Japan). There were spontaneous synaptic currents with a slow time course mixed with fast ones, attributable to electrical coupling of muscle cells with neighbors (Gho, 1994; Kidokoro and Nishikawa, 1994; Ueda and Kidokoro, 1996). In this study only synaptic currents with a fast time course were counted. For nerve stimulation, a microelectrode filled with $4 \mathrm{M}$ K-acetate was inserted in the middle of the ventral ganglion, and positive pulses of $\sim 2 \mu \mathrm{A}$ in intensity and $2 \mathrm{msec}$ in duration were delivered.

Solutions. The ionic composition of the solutions used in the experiments are as follows (in mM). In normal external saline: $140 \mathrm{NaCl}, 2 \mathrm{KCl}$, $5.5 \mathrm{MgCl}_{2}, 0.5 \mathrm{CaCl}_{2}$, and $5 \mathrm{HEPES}-\mathrm{NaOH}, \mathrm{pH} \mathrm{7.1.} \mathrm{In} \mathrm{Ca}^{2+}$-free external solution: $140 \mathrm{NaCl}, 20 \mathrm{KCl}, 6 \mathrm{MgCl}_{2}$, and $5 \mathrm{HEPES}-\mathrm{NaOH}, \mathrm{pH}$ 7.1. The ionic composition of the internal solution was (in $\mathrm{mM}$ ): 158 CsCl, 1 Mg-ATP, 5 EGTA, and 10 HEPES-NaOH, pH 7.1. Tetrodotoxin (TTX) was purchased from Sigma.

\section{RESULTS}

\section{Generation of $\boldsymbol{n}$-syb mutations}

The Drosophila neuronal-synaptobrevin gene, $n$-syb, is located on the left arm of the third chromosome at the border between polytene bands 62A and 62B (DiAntonio et al., 1993a). Because no preexisting mutations or chromosomal aberrations affected $n$-syb (data not shown), we decided to mutate the gene by mobilizing a P-element transposon. Because these elements, when mobilized by the transposase, are predisposed to insert themselves in the vicinity of their site of origin (Tower et al., 1993), we sought a P-element-containing line that carried an insertion within $100 \mathrm{~kb}$ of $n-s y b$. We obtained a line of flies (line 34) containing a PlacW-type P-element insertion at the border between polytene bands 62A and 62B (Gonczy et al., 1992). PlacW P-elements contain the bacterial origin of replication and the ampicillin resistance gene, permitting the isolation of the DNA sequences flanking the site of the P-element insertion (Bier et al., 1989). The DNA sequence flanking the line 34 P-element insertion was isolated by digesting line 34 genomic DNA with EcoRI, circularizing it with T4 DNA ligase, and using the resulting plasmid to transform bacteria. To determine how close the line 34 P-element insertion was to the $n$-syb gene, we inquired whether it fell within the same P1 clone (genomic clones containing 70-95 $\mathrm{kb}$ of genomic DNA) as the $n$-syb gene. Five P1 clones spanning the region from early $62 \mathrm{~A}$ to late $62 \mathrm{~B}$ were obtained from Drosophila Genome Center, digested, electrophoresed, blotted, and hybridized with probes derived from the $n$-syb gene and from the sequence surrounding the line $34 \mathrm{P}$-element insertion (Fig. 1A). Of these, one P1 clone (17-42; lane 1) was recognized by both probes, whereas others contained either the $n$-syb region (29-89 and 39-43; lanes 2 and 3 ) or the P-element site of insertion (55-41; lane 5), but not both. Because clone 17-42 hybridized with both probes, the distance between the P-element insertion and the $n-s y b$ gene could not exceed $100 \mathrm{~kb}$, the maximum size of the insert in a P1 clone.

The P-element was mobilized by crossing it to a line expressing a constant source of transposase (Fig. $1 B$ ). Flies containing both the P-element and the source of transposase (700 males and 750 females) then were crossed individually to $y w$ flies. The F2 progeny from each vial were examined, and a single male containing a likely additional P-element insertion (based on a darker eye phenotype) was selected from each vial. 900 novel insertions were selected, and these flies then were screened to see if any of the new P-element insertions landed in or near the $n$-syb gene via a modification of the plasmid rescue procedure (Zinsmaier et al., 1994). Two insertions were identified near the $n$-syb gene. One, called F82, has a P-element insertion $3-4 \mathrm{~kb} 3^{\prime}$ of the $n$-syb gene (in addition to the starter P-element from line 34 ) and apparently did not disrupt the $n-s y b$ transcript because it was homozygousviable. A second insertion landed $150 \mathrm{bp}$ upstream of the initiation ATG and was homozygous-lethal. We will designate this mutation $n-s y b^{\mathrm{F} 33}$. The position of the F33 insertion was determined by sequencing the rescued P-element plasmid, by PCR with primers to the $31 \mathrm{bp}$ repeat of the P-element and to exon 1 sequences of $n-s y b$, and by Southern blotting, as shown in Figure $1 C$. The Southern blot revealed that the P-element had inserted in a $2 \mathrm{~kb} E c o$ RI fragment just $5^{\prime}$ to the $n$-syb ORF.

Several lines of evidence indicate that the lethality of $n-s y b^{\mathrm{F} 33}$ is attributable to the insertion near $n-s y b$. When the F33 insertion was recombined away from the starter line 34 P-element, the lethality remained with the F33 insertion. Furthermore, when the P-element in F33 was excised precisely (by reintroducing the transposase), homozygous-viable lines were generated, indicating that the lethality was attributable to the insertion. Southern blot analysis of the viable excision lines revealed that the P-element precisely or nearly precisely excised in four of seven lines (Fig. $1 D$, lanes 1, 2, 6, and 7), and in the remaining three lines (Fig. 1D, lanes 3, 4, and 5) only several hundred base pairs of the P-element remained behind. Lines that retained larger fragments of the P-element remained lethal.

$n-s y b^{\mathrm{F} 33}$ is a severe allele of $n-s y b$ (it is an embryonic-lethal), but because the insertion does not interrupt the ORF of $n$-syb, this allele might produce some $n$-syb protein; thus by analyzing its phenotype, we might underestimate the role of $n$-syb. We therefore generated an unambiguous null mutation by imprecise P-element excision. From $\sim 700$ excisions, 105 lines were identified that were lethal in combination with $n$-syb $b^{\mathrm{F} 33}$. Additional deletions were generated by excising the F82 P-element. Many of the excisions were internal deletions of the F33 P-element (identified by using PCR primers to the $31 \mathrm{bp}$ repeat of the P-element and to exon 1 of $n$-syb; see Fig. $2 A$, bottom) and were unlikely to 

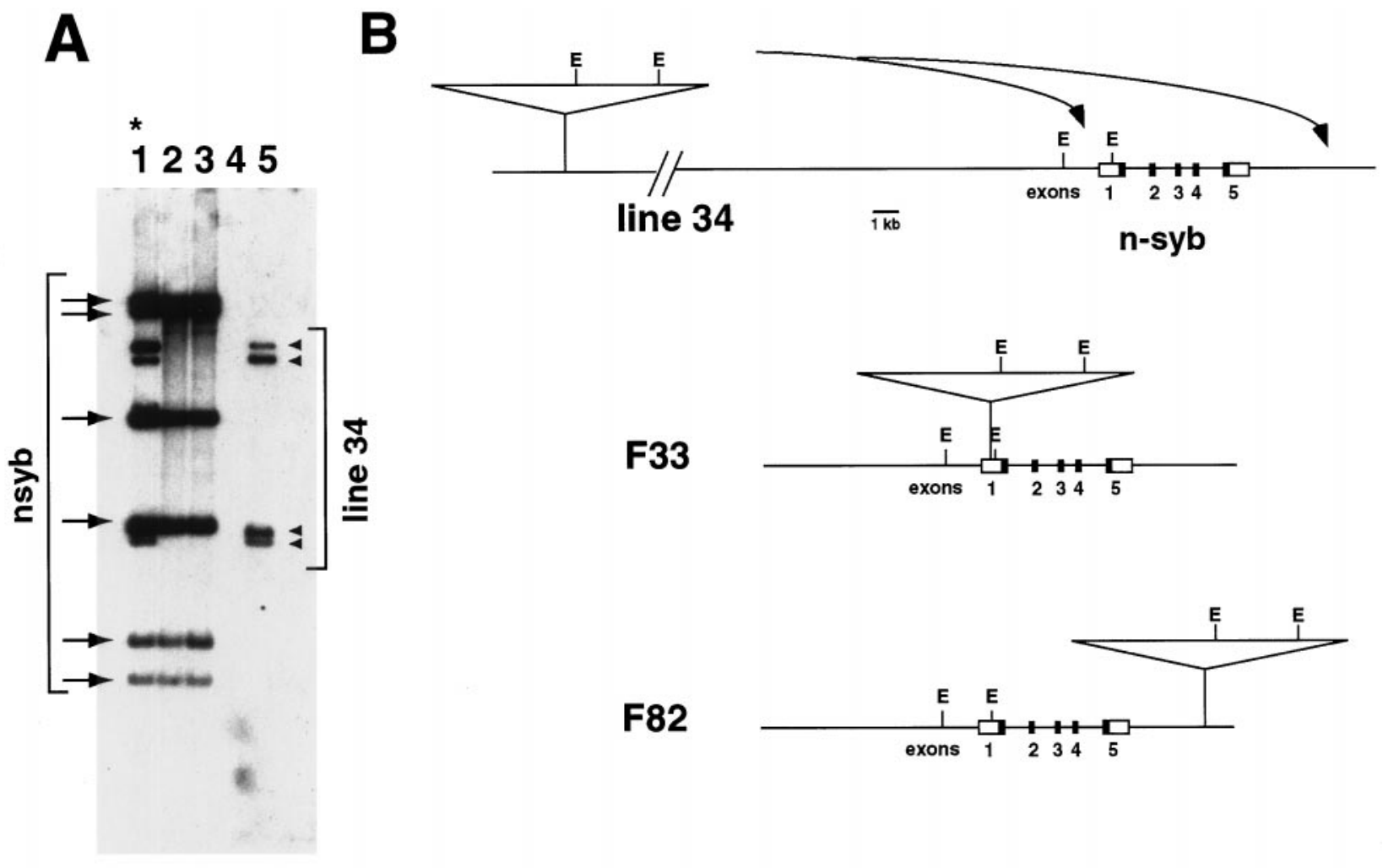

F33

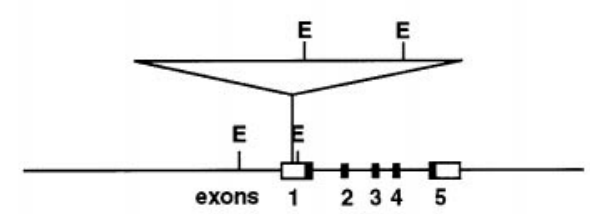

F82
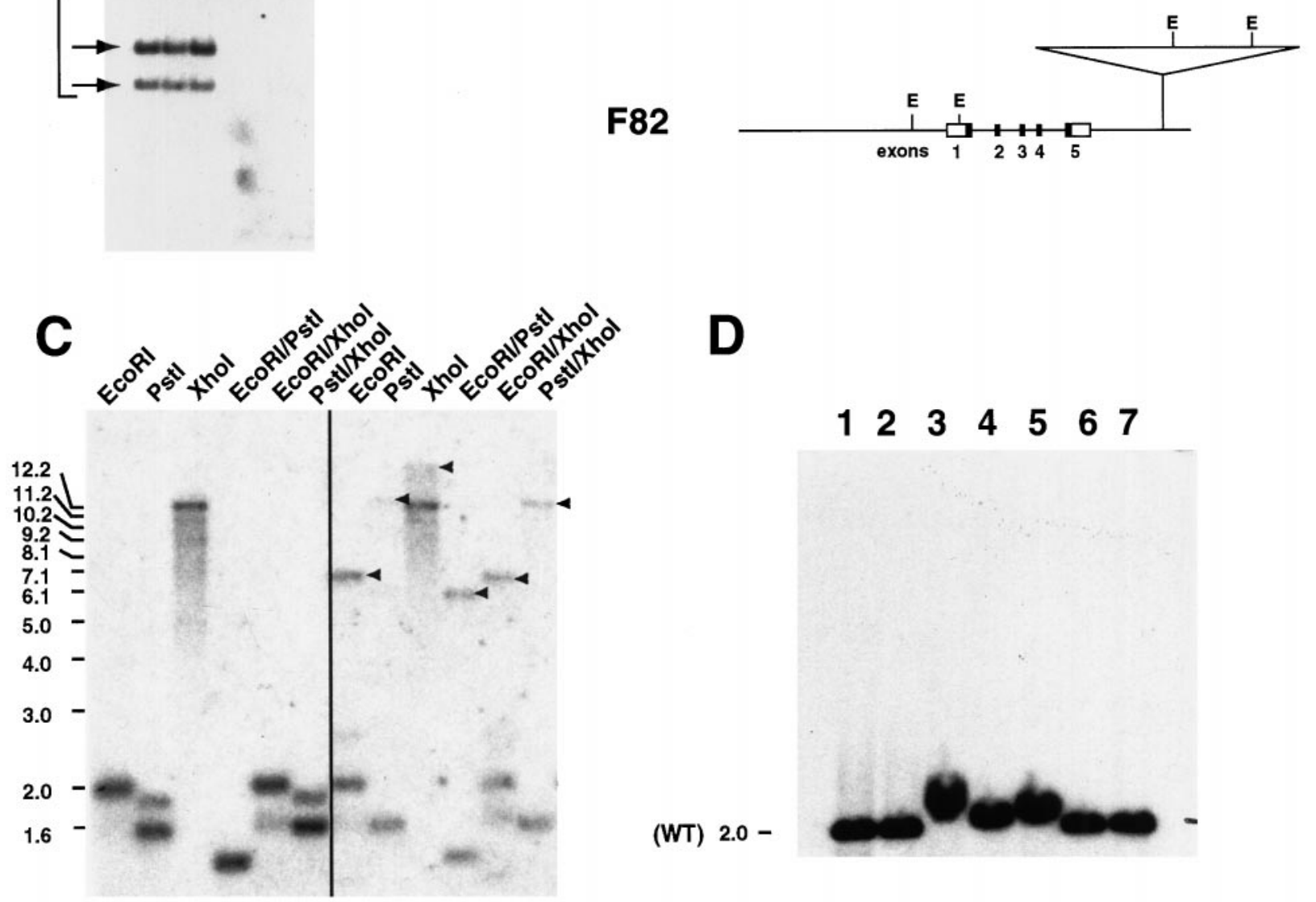

(WT)

D

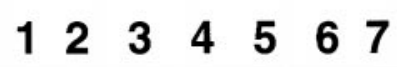

Figure 1. Mapping of P-element insertions near the $n$-syb locus. A, Lanes 1-5 contain, in order, $\mathrm{P} 1$ genomic clones 17-42, 29-89, 39-43, 40-41, and 55-41 from polytene bands 62A and 62B. Their DNA was digested with $B g l \mathrm{II}$ and XhoI and simultaneously probed with $n$-syb probe and the flanking sequence from the starter P-element. $n$-syb-specific bands are indicated with arrows, and the P-element flanking sequence is indicated with arrowheads. 17-42 hybridizes with both probes (asterisk). B. Map of P-elements near $n$-syb. The P-element upstream of $n$-syb in line 34 was mobilized (arrows) to give rise to the insertions in F33 and F82. Untranslated exon sequences are indicated by open boxes, translated exons by shaded boxes, and EcoRI sites by the letter E. Top, Although the orientation of the P-element and the $n$-syb gene and the distance between the two have not been determined, they must fall within $\sim 100 \mathrm{~kb}$ of each other to be contained on P1 17-42. Middle, The F33 P-element inserted in exon 1 of the $n$-syb gene 150 bp from the initiation ATG. Bottom, The F82 P-element inserted 3-4 kb from the $3^{\prime}$ end of $n$-syb. $C$, Southern blot of genomic DNA from wild-type (left) and F33/TM3, Sb heterozygote (right). Lanes are digested with the indicated restriction enzymes, and the molecular weights of the bands are indicated in kilobase pairs. Both blots are probed with a $2 \mathrm{~kb}$ EcoRI fragment of $n$-syb from the $5^{\prime}$ untranslated region. Arrowheads indicate new bands that result from the F33 insertion. D, Southern blot of viable, revertant excision lines. Lanes 1-7 are genomic DNA from seven different F33 excisions digested with $E c o$ RI and probed with a $2 \mathrm{~kb} E c o \mathrm{RI} n$-syb genomic fragment. The wild-type band of $2 \mathrm{~kb}$ is indicated, and all of the excisions are within $200-300 \mathrm{bp}$ of the wild-type size. 
A

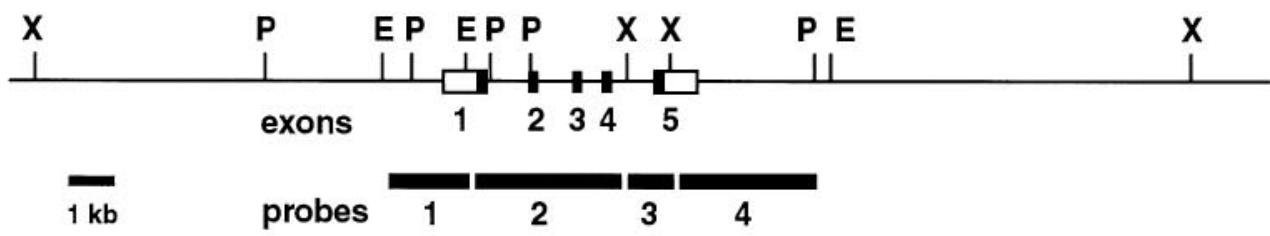

Genotype

Wild Type

$1 \mathrm{~kb}$

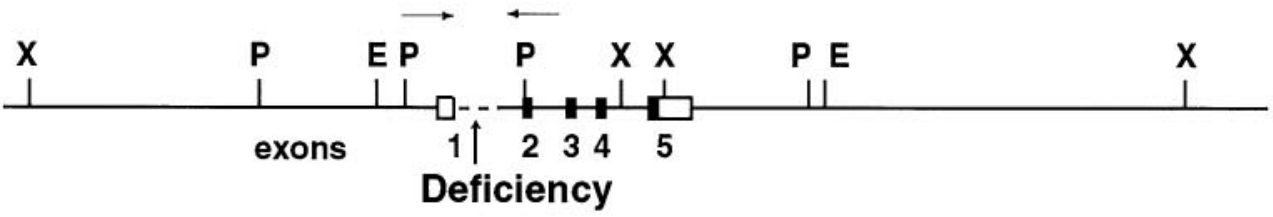

n-syb

$\Delta$ F33-8

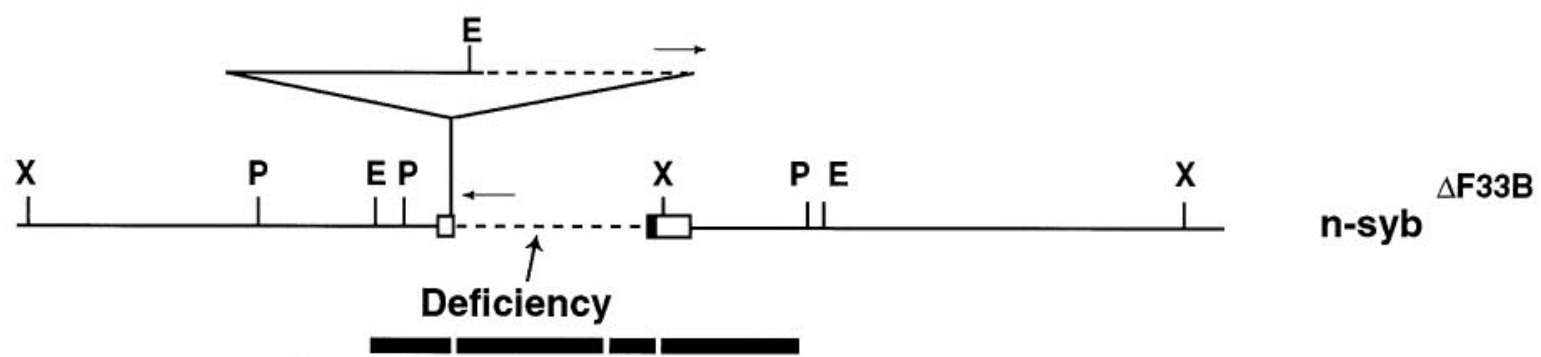

B

probes $\begin{array}{lllll}1 & 2 & 3 & 4\end{array}$

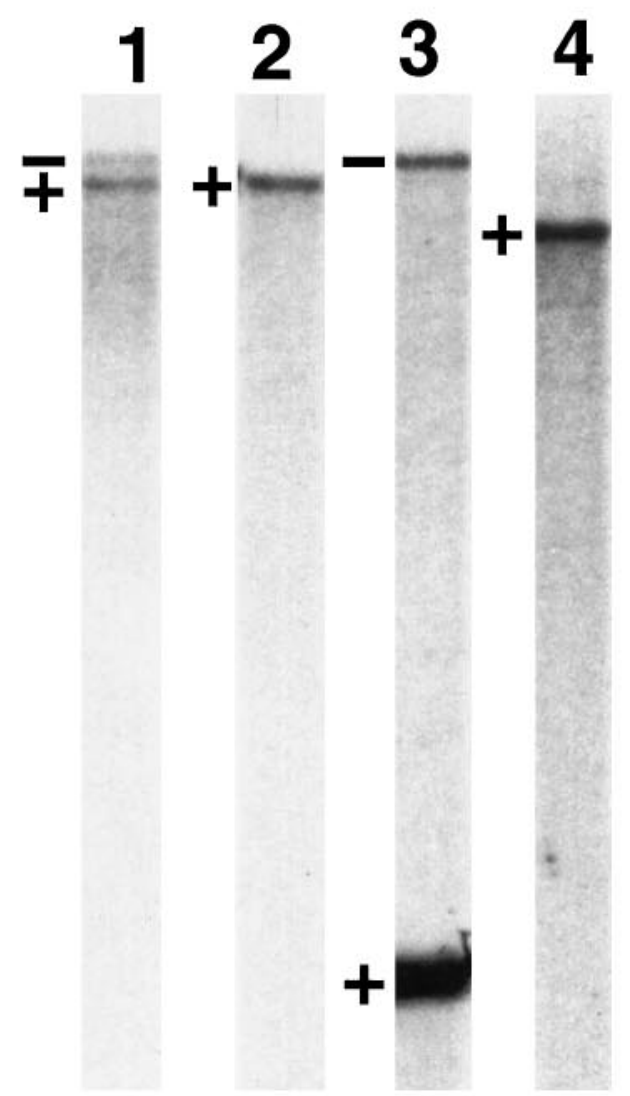

Figure 2. Restriction mapping of excision alleles. A, Restriction map of the $n$-syb locus (top), the excision allele $n$-syb ${ }^{\Delta \mathrm{F} 33-8}$ (middle), and the excision allele $n$-syb $b^{\Delta \mathrm{F} 33 \mathrm{~B}}$ (bottom). The restriction site abbreviations are the following: EcoRI, E; XhoI, X; PstI, P. Deficiencies are indicated by a dashed line, PCR primers are shown as arrows, and exons are shown as boxes (shaded boxes are coding regions, and unshaded boxes are noncoding regions). Probes used in $B$ are diagrammed below the wild-type $n$-syb and the $n$-syb ${ }^{\Delta \mathrm{F} 33 \mathrm{~B}}$ loci. B, Genomic Southern blots of DNA (Figure legend continues) 


\begin{tabular}{llll}
\hline Table 1. Summary of $\boldsymbol{n}$-syb alleles & & \\
Allele & Type of mutation & Severity & Phenotype \\
\hline F33 & P insertion & Nearly null & Embryonic lethal \\
$\Delta$ F33B & Excision & Null & Embryonic lethal \\
$\Delta$ F3300 & Excision & Likely null & Embryonic lethal \\
$\Delta$ F33-8 & Excision & Likely null & Embryonic lethal \\
$\Delta$ F82C & Excision & Likely null & Embryonic lethal \\
I4 & EMS & Hypomorph & Viable, sluggish \\
I18 & EMS & Hypomorph & Viable, sluggish
\end{tabular}

Summary of $n$-syb alleles and their phenotypes. The phenotype described is for the given allele in the homozygous state, with the exception of I4 and I18. The phenotype described for I4 and I18 is over the null allele $n-s y b^{\Delta \mathrm{F} 33 \mathrm{~B}}$.

produce a mutation more severe than the original F33 insertion. Several lines, however, deleted portions of the $n$-syb gene: $\Delta \mathrm{F} 33 \mathrm{~B}$, $\Delta \mathrm{F} 33 \mathrm{OO}, \Delta \mathrm{F} 82 \mathrm{C}, \Delta \mathrm{F} 33-8$, and $\Delta \mathrm{F} 82 \mathrm{C}$. In $\Delta \mathrm{F} 33 \mathrm{~B}$ and $\Delta \mathrm{F} 33-8$ the extent of the deletions was determined (Fig. $2 A$ ). In $\Delta$ F33-8 the EcoRI site just $3^{\prime}$ to the F33 insertion and the $3^{\prime}$ end of exon 1, including the initiation ATG, was deleted, as judged by Southern blotting (data not shown). The deletion extended into intron 1 but did not extend into exon 2, nor did the deletion extend $5^{\prime}$ from the F33 insertion site, as determined by PCR, between a primer $5^{\prime}$ of the insertion and an exon 2 primer (see Fig. $2 A$, middle). The deletion of the initiation ATG in $\Delta \mathrm{F} 33-8$ caused an abnormal protein to be made (see below).

A greater portion of the $n-s y b$ gene was deleted in $\Delta \mathrm{F} 33 \mathrm{~B}$. Southern blots indicated that much of exon 1 (including the start codon) and all of exons 2, 3, and 4 were removed (Fig. 2B). The deletion produced by the $\Delta \mathrm{F} 33 \mathrm{~B}$ excision removed the first 122 of the 181 amino acids of $n$-syb. The remaining portion consisted of seven amino acids from the membrane-spanning domain and 52 from the intravesicular tail; thus, in the unlikely event that it was translated, it still would lack all of the functionally important and conserved domains, including those responsible for binding to syntaxin and SNAP-25. Thus $n-s y b^{\Delta \mathrm{F} 33 \mathrm{~B}}$ constitutes a null mutation. Further $n$-syb alleles were generated by performing an F2 lethal screen. Flies were treated with the chemical mutagen ethyl methane sulfonate (EMS), which often induces point mutations. These flies were crossed to a third chromosome balancer stock, and the resulting F1 males were crossed to the original $n-s y b^{\mathrm{F} 33}$ allele so that flies that failed to complement $n-s y b^{\mathrm{F} 33}$ could be selected. Two alleles, $n-s y b^{\mathrm{I} 4}$ and $n-s y b^{\mathrm{I} 18}$, were isolated and found to be hypomorphic alleles of $n-s y b$; in combination with $n-s y b^{\mathrm{F} 33}$ or $n-s y b^{\Delta \mathrm{F} 33 \mathrm{~B}}$, the EMS alleles can survive until adulthood, but they are very sluggish and often remain motionless for minutes at a time.

A summary of the mutations is listed in Table 1. Seven alleles were isolated; they range from weak hypomorphic alleles that clearly retain $n$-syb function to nulls. The severe alleles were embryonic-lethals, whereas the weaker alleles were viable even as adults. To establish the function of $n-s y b$, we concentrated on characterizing the phenotype of the null allele $n-s y b^{\Delta \mathrm{F} 33 \mathrm{~B}}$.

\section{$\boldsymbol{n}$-syb protein is enriched in synapses}

To examine the distribution of $n-s y b$ protein, we raised an antiserum against the intravesicular tail of $n-s y b$, a region that shares no homology to other synaptobrevins, including the synaptobrevin ubiquitously expressed in Drosophila, synaptobrevin (syb) (see Materials and Methods). This affinity-purified antiserum recognizes a band of $\sim 22 \mathrm{kDa}$, which is enriched in Drosophila heads relative to the rest of the body (Fig. $3 A$, wt heads vs wt bodies). Heads from mutant heterozygotes were analyzed with this antiserum (Fig. $3 A$ ) to characterize the mutations further. The 22 $\mathrm{kDa}$ band representing wild-type protein was seen, as expected, in all of the heterozygotes and in the parental line (line 34). In the mutants, however, the signal was decreased, as predicted by the loss of one of the two copies of the $n-s y b$ gene. Longer exposures of Western blots of protein extracts from the $n$-syb mutant heterozygotes revealed that the $n-s y b^{\mathrm{F} 33-8}$ mutant produced a faint band at a slightly higher molecular weight than the wild-type $n$-syb protein (data not shown). To examine this band more closely, we subjected a more concentrated protein extract from $n-s y b^{\Delta \mathrm{F} 33-8}$ heterozygotes to SDS-PAGE, blotted the extract, and probed it with the anti- $n-s y b$ antiserum. The results of this Western blot are shown in Figure $3 B$. A band running just above the wild-type $n$-syb band is evident. In that mutant a deletion removes the normal initiation ATG (see above), but the presence of a higher molecular weight protein suggests that an upstream, inframe ATG from intron 1 was used to make a larger protein. In $n-s y b^{\Delta \mathrm{F} 33 \mathrm{~B}}$, no lower molecular weight band arises; thus, in this deletion, the fragment of the intravesicular tail that theoretically might be produced is not present at appreciable levels.

To localize the $n-s y b$ product in the embryo, we double-stained dissected preparations with this affinity-purified anti- $n-s y b$ antiserum and an anti-Fasciclin II antibody. In Figure $4 A$, the $n$-syb staining is strong and uniform in the ventral nerve cord (VNC), and faint staining is seen in axon commissures and segmental and intersegmental nerves that could represent vesicles en route to synapses. In the absence of the primary antibody, no staining was observed (data not shown).

The presence of $n$-syb protein at the neuromuscular junctions (NMJs) on muscles 6 and 7 of a wild-type embryo was demonstrated by labeling with anti-Fasciclin II antibody to identify the nerve (Fig. $4 B$ ) and with the affinity-purified anti- $n$-syb antiserum (Fig. $4 C$ ). The $n$-syb staining is concentrated in the synaptic zones at the NMJ. Thus, the subcellular localization of $n$-syb is consistent with an important role in synaptic function, and its presence at this synapse enables us to characterize the physiological consequences of the mutations at this well characterized synapse.

\section{$n$-syb is not required for formation of the NMJ, but null mutants are paralyzed}

The extension of growth cones during neural development is thought to involve the addition of membrane. Because membrane addition at the mature synapse involves SNARE proteins and because inhibition of SNAP-25 expression was shown to inhibit

\section{$\leftarrow$}

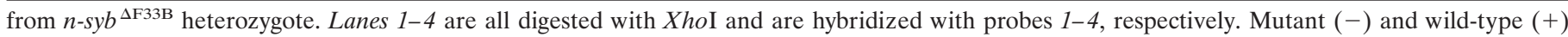

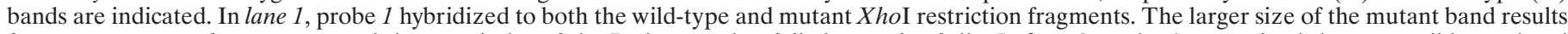

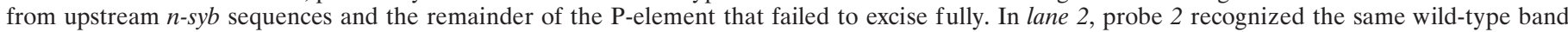

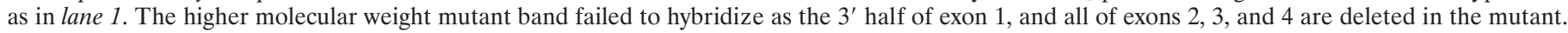

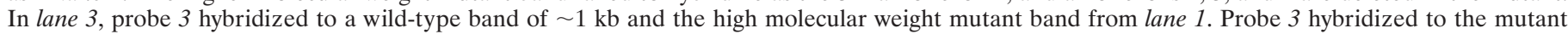

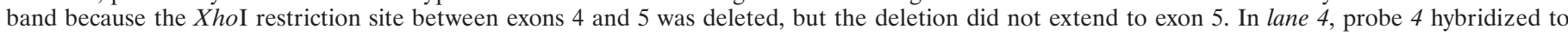
a single unaltered band because the probe is outside the deleted region. 


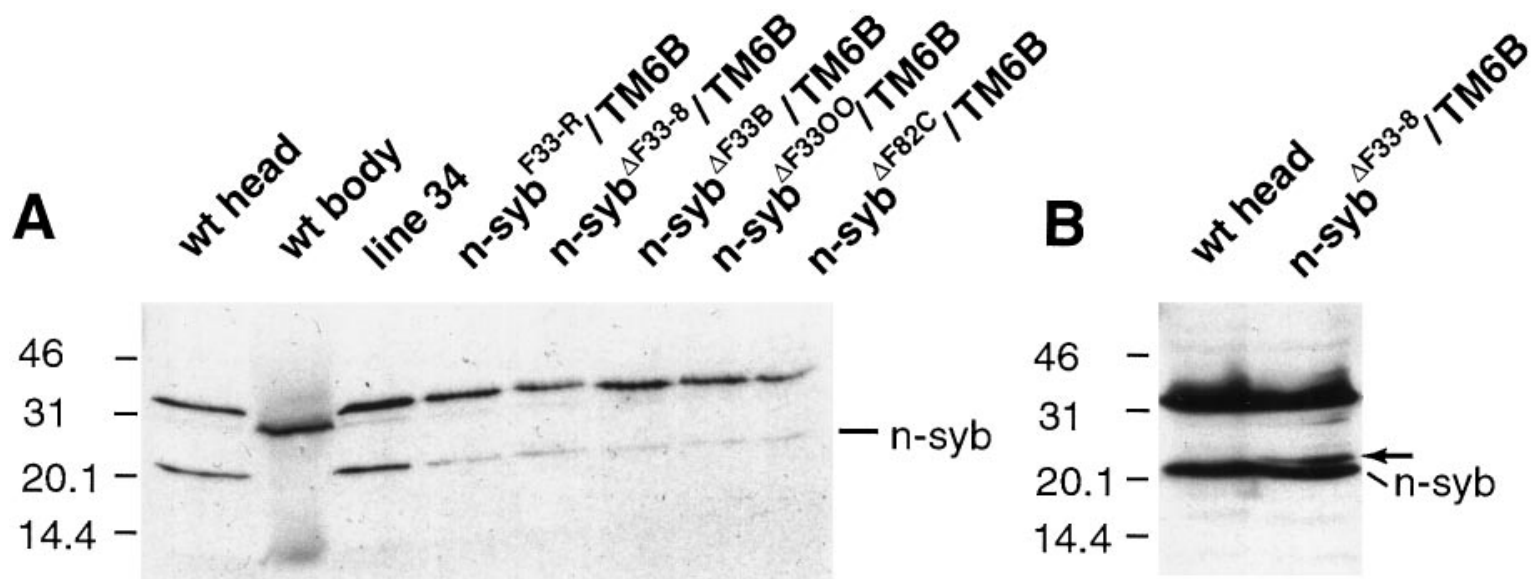

Figure 3. Western blots of protein extracts from wild-type and $n$-syb mutant heterozygotes probed with anti- $n$-syb antiserum. The molecular weight size markers are in kilodaltons, and the band corresponding to size of the $n$-syb protein $(\sim 22 \mathrm{kDa})$ is indicated. Proteins extracts from either 10 heads or 10 bodies $(A)$ or 20 heads $(B)$ from the indicated lines were prepared as described in Material and Methods. $A, n$-syb protein is enriched in wild-type (wt) heads as compared with the rest of the body (wt body); the starter P-element line, line 34, has wild-type levels of $n$-syb. All of the $n$-syb mutant heterozygotes have reduced levels of $n$-syb protein. $B, n-s y b^{\Delta \mathrm{F} 33-8}$ produces a slightly higher molecular weight form of $n$-syb (indicated with an $a r r o w$ ) than wild type. This is most likely attributable to the use of an alternative initiation ATG in intron 1 . The higher molecular weight band present in all of the lanes, running at $\sim 35 \mathrm{kDa}$, appears to be a protein that cross-reacts with the $n$-syb antiserum because it does not decrease in intensity in the $n$-syb mutants.

axonal growth both in vivo and in vitro (Osen-Sand et al., 1993), we therefore examined whether $n$-syb is necessary for axonal outgrowth. $n$-syb $b^{\Delta \mathrm{F} 33 \mathrm{~B}}$ null mutants were stained with antiFasciclin II antibody (Fig. 4D,F). The longitudinal tracts of the $\mathrm{VNC}$, the motor nerves, and the terminals of the motor neurons all appeared normal despite the absence of $n$-syb. When null mutants were stained with anti- $n$-syb antisera, no staining was observed in VNC or motor nerves or the motor neuron terminals (Fig. 4E,G). Despite the normal appearance of the VNC and motor neurons, late stage $n-s y b^{\Delta \mathrm{F} 33 \mathrm{~B}}$ homozygous embryos failed to move unless probed and never hatched from their egg cases.

\section{Evoked neurotransmitter release is blocked in $n$-syb null mutant}

To assess the role of $n-s y b$ in evoked neurotransmitter release, we recorded from stimulated embryonic NMJs, using whole-cell patch-clamp methods. Late embryos, homozygous for the $n-s y b^{\Delta \mathrm{F} 33 \mathrm{~B}}$ deletion or the $n-s y b^{\mathrm{F} 33-\mathrm{R}}$ insertion, were dissected to expose the CNS and longitudinal muscles. Line 34 embryos were used as controls. A patch electrode recorded synaptic currents from muscle 4, 6, or 7 while the ventral ganglion was stimulated at $0.3 \mathrm{~Hz}$. In $n$-syb $b^{\Delta \mathrm{F} 33 \mathrm{~B}}$ and $n-s y b^{\mathrm{F} 33-\mathrm{R}}$ mutant embryos, stimulation of the nerve failed to elicit any evoked currents in the muscle (Fig. $5)$. In the parental controls, stimulation produced currents in excess of $500 \mathrm{pA}$ in $0.5 \mathrm{mM} \mathrm{Ca}^{2+}$. Increasing the external $\mathrm{Ca}^{2+}$ concentration to $6 \mathrm{~mm}$ did not restore a detectable excitatory synaptic current (ESC) in the $n$-syb null. A potassium channel blocker, 4-aminopyridine (4-AP), is known to enhance synaptic transmission in Drosophila larvae, presumably by increasing $\mathrm{Ca}^{2+}$ influx (Jan and Jan, 1977). Therefore, 2 mM 4-AP was included in $2 \mathrm{mM} \mathrm{Ca}^{2+}$ external saline. Still no synaptic currents were evoked in $n-s y b^{\Delta \mathrm{F} 33 \mathrm{~B}}$ embryos (four cells were tested in three preparations). In contrast, prominent bursts of synaptic currents were observed in line 34 larvae with $1 \mathrm{~mm} 4-\mathrm{AP}$ with $0.5 \mathrm{~mm} \mathrm{Ca}^{2+}$ (data not shown). Thus, $n$-syb appears to be required for nerveevoked release of neurotransmitter.

\section{Spontaneous neurotransmitter release is reduced, but not abolished, in $\boldsymbol{n}$-syb null mutant}

Miniature excitatory synaptic currents (mESCs) at the NMJ are thought to arise from single synaptic vesicles fusing spontaneously with the presynaptic terminal membrane. To investigate the role of $n-s y b$ in this spontaneous release, we recorded mESCs at the NMJ of embryos homozygous for the $n-s y b^{\Delta \mathrm{F} 33 \mathrm{~B}}$ deletion or the $n-s y b^{\mathrm{F} 33-\mathrm{R}}$ insertion. Again, the parental line 34 was used as a control. Recordings were performed in the presence of $3 \mu \mathrm{M}$ TTX to eliminate nerve-evoked release, and the frequency of spontaneous events was recorded. The mESC frequency was reduced in both $n$-syb mutations by $\sim 75 \%$, as compared with line 34 controls (Fig. 6). These differences were statistically significant $(p<0.05)$. These results are in general agreement with previous reports in which the light chain of tetanus toxin was expressed in the Drosophila nervous system to reduce the level of $n$-syb (Broadie et al., 1995; Sweeney et al., 1995). Thus, $n$-syb appears to play a role in at least some of the spontaneous neurotransmitter release, but $n-s y b$ is not essential for spontaneous release.

To examine the mESCs more closely, we found that it was necessary to increase their frequency somewhat by depolarizing with high $\mathrm{K}^{+}$in $0.5 \mathrm{~mm} \mathrm{Ca}^{2+}$ in the presence of TTX to prevent action potentials. Representative traces of the mESCs from the different genotypes are shown in Figure $7 \mathrm{Aa}-\mathrm{Ca}$. From many such records the mean amplitude of mEPCs was calculated also. No significant difference in amplitude was observed between the control and $n$-syb mutant lines. The mean amplitudes were 155 $\mathrm{pA} \pm 26 \mathrm{pA}(n=5)$ for $n-s y b^{\Delta \mathrm{F} 33 \mathrm{~B}}, 199 \pm 16 \mathrm{pA}(n=7)$ for $n-s y b^{\mathrm{F} 33-\mathrm{R}}$, and $168 \mathrm{pA} \pm 24 \mathrm{pA}(n=6)$ for the control line 34 , where $n$ is the number of cells. The amplitudes of the mESCs were spread over a wide range of values (Fig. $7 \mathrm{Ab}-\mathrm{Cb}$ ) that may reflect some instances of the simultaneous release of more than one vesicle. Both the control line 34 and the $n$-syb ${ }^{\Delta \mathrm{F} 33 \mathrm{~B}}$ mutant show a similar amplitude distribution, with the largest number of events in the $\sim 50 \mathrm{pA}$ range and a pattern of smaller peaks at increasing current amplitudes. The mutant $n-s y b^{\mathrm{F} 33-\mathrm{R}}$ has many 

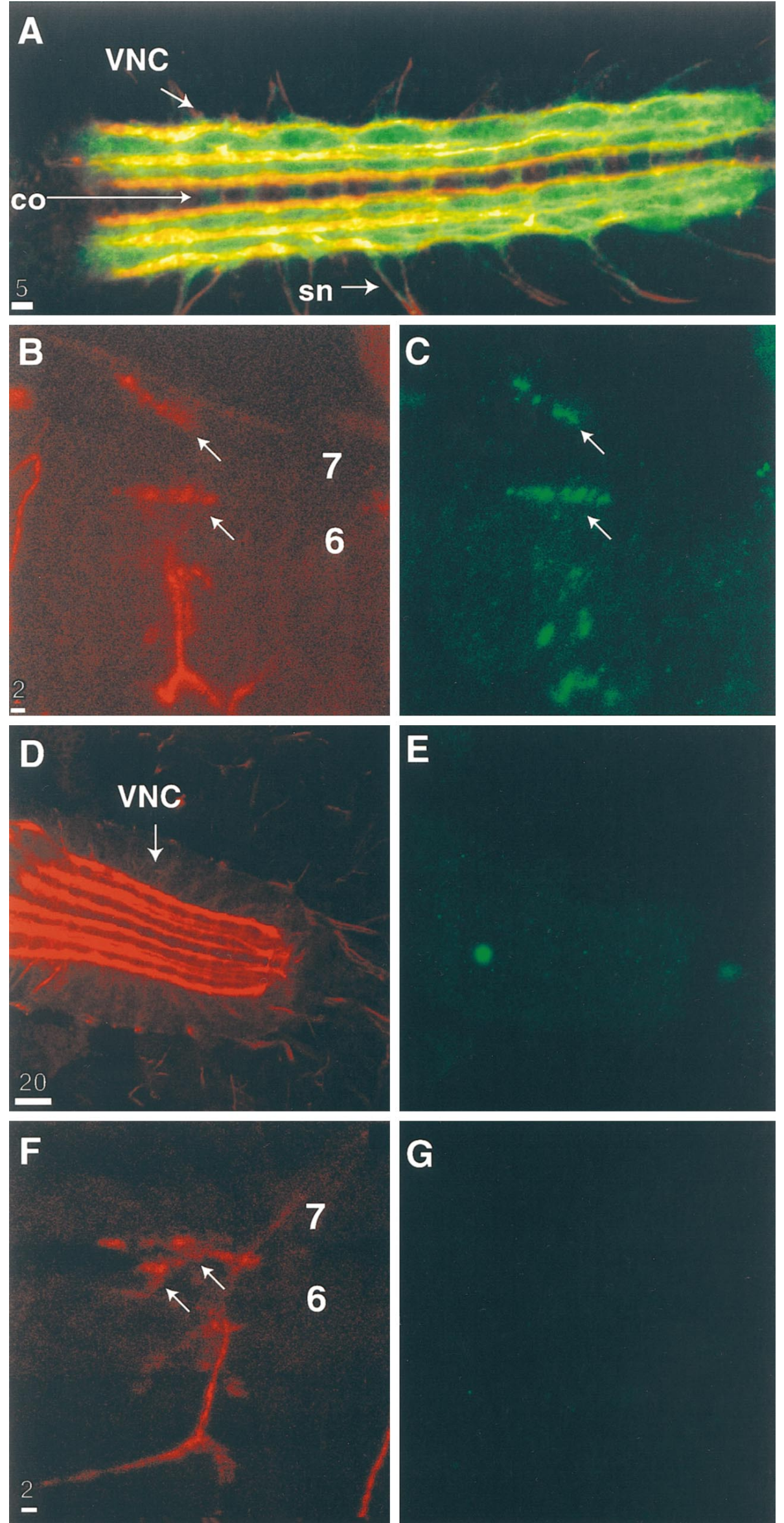

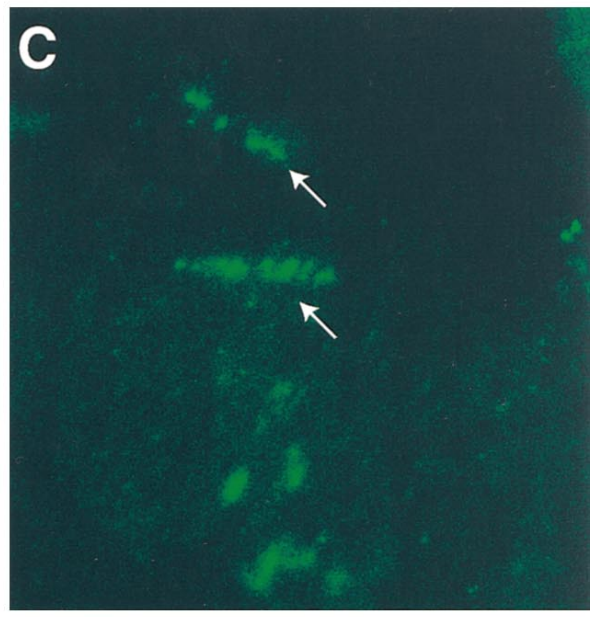

E

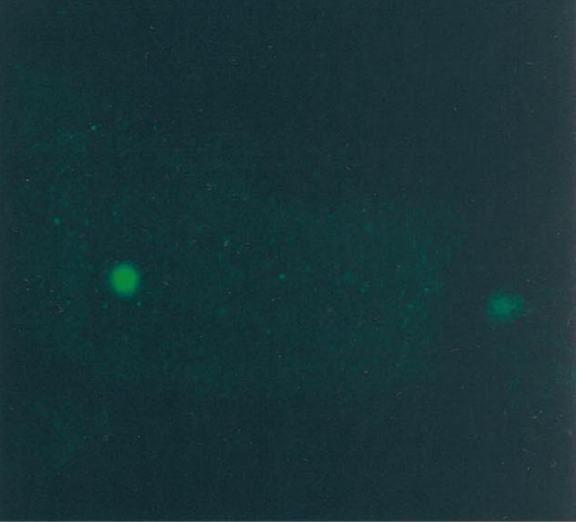

G
Figure 4. Immunocytochemistry of wild-type and $n$-sy $b$ mutant embryos. $A$, Wild-type embryo fillet double-stained with $n$-syb antiserum (green) and Fasciclin II antibody (red). B, C, Synapses (arrows) at a wild-type NMJ stained for FasII $(B)$ and $n$-syb $(C) . D-G, n$-syb null mutants $\left(n-s y b^{\Delta \mathrm{F} 33 \mathrm{~B}}\right)$ stained for FasII $(D, F)$ and $n$-syb $(E, G)$. Despite the absence of detectable $n$-syb, the morphology of the nerve cord and NMJ appears normal. Ventral nerve cord, $V N C$; axonal commissures, $\mathrm{Co}$; axons of the segmental nerves, $S N$; longitudinal muscles 6 and 7, 6, 7 . Scale bar, $1 \mu \mathrm{m}$. 


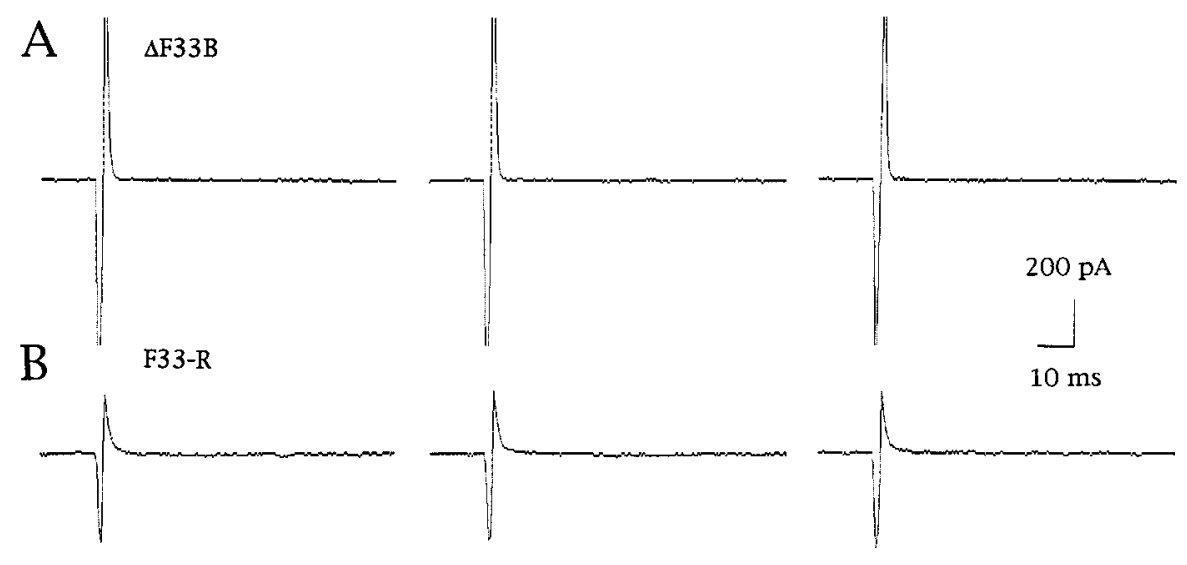

Figure 5. Nerve-evoked synaptic currents are absent from the neuromuscular junctions of $n$-syb mutants stimulated at $0.3 \mathrm{~Hz}$. Evoked currents are lacking in $n$-syb null mutant $n$-syb ${ }^{\Delta \mathrm{F} 33 \mathrm{~B}}(A)$ and in the mutant $n-s y b^{\mathrm{F} 33-\mathrm{R}}(B)$ but are present in the parental control, line $34(C)$. The external solution contained $2 \mathrm{mM} \mathrm{Ca}^{2+}$ for lines $n-s y b^{\Delta \mathrm{F} 33 \mathrm{~B}}$ and $n-s y b^{\mathrm{F} 33-\mathrm{R}}$ and $0.5 \mathrm{mM} \mathrm{Ca}^{2+}$ for line 34 .

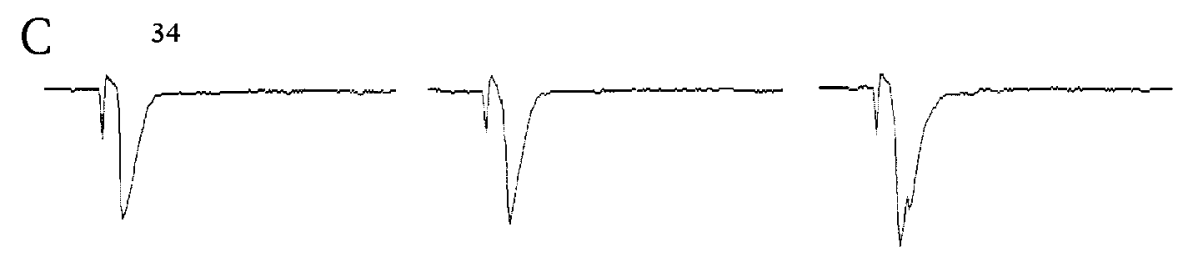

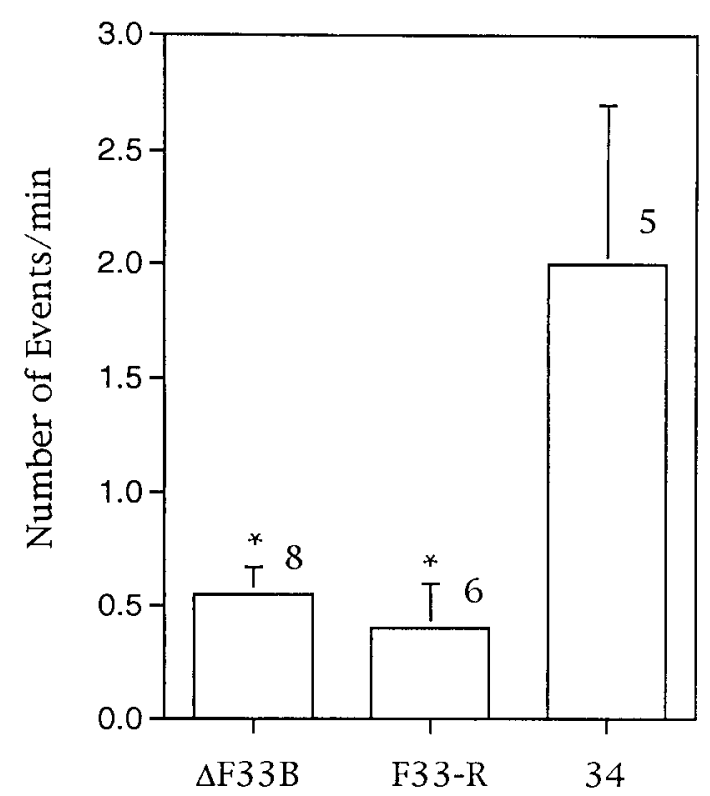

Figure 6. Frequency of miniature synaptic currents in $n$-syb $b^{\mathrm{AF} 33 \mathrm{~B}}$, $n-s y b^{\mathrm{F} 33-\mathrm{R}}$, and line 34. Error bars are SEM. Asterisks denote statistical differences from line 34 at $p<0.05$ by the ANOVA test. Numbers indicate the number of cells examined. Miniature synaptic currents were recorded in the presence of $3 \mu \mathrm{M}$ TTX in $0.5 \mathrm{mM} \mathrm{Ca}^{2+}$ saline.

events in the $50 \mathrm{pA}$ range, but it also has somewhat more events than the other lines in the 100 and $200 \mathrm{pA}$ range. Interestingly, the lack of a major synaptic vesicle protein appears to have had little effect on the formation of synaptic vesicles or on the amount of neurotransmitter contained within the vesicles, as judged by the persistence of spontaneous events and their unaltered amplitude. Moreover, the responsiveness of the postsynaptic membrane must be roughly unchanged, and so the failure of nerve stimulation to evoke an ESC cannot be attributed to changes in postsynaptic sensitivity or transmitter packaging.

\section{DISCUSSION}

We have described the generation of mutations in the $n$-syb gene in Drosophila melanogaster. Among the alleles we generated is a deletion mutation, $n-s y b^{\Delta \mathrm{F} 33 \mathrm{~B}}$, that removes most of the ORF and, by this molecular criterion as well as by protein analysis on immunoblots and immunocytochemistry, can be judged to be a null allele. $n-s y b$ protein and mRNA are not present in early embryos and therefore are not maternally deposited in the egg (DiAntonio et al., 1993a; D. Deitcher, unpublished data). Thus the homozygous null phenotype represents the complete absence of this gene product.

Embryos homozygous for this mutation are lethal and nearly paralyzed. From a morphological and electrophysiological analysis of these embryos, two major findings have emerged and are discussed below: (1) the outgrowth of axons and the formation of synapses is independent of the $n-s y b$ protein, and (2) spontaneous mESCs can occur without $n-s y b$, whereas the action potentialevoked ESC cannot.

\section{$n$-syb is required for synaptic function, but not synapse formation}

Because the outgrowth of axons and the establishment of synapses require the addition of vesicles to the growth cone, we inquired whether or not this process involved $n$-syb. In the case of vertebrates, SNAP-25 and syntaxin, the same exocytotic proteins that function at the synapse, have been implicated in axon outgrowth as well (Osen-Sand et al., 1993; Igarashi et al., 1996). In Drosophila, two synaptic proteins, syntaxin and the n-sec homolog rop, have been shown to affect membrane trafficking in nonneuronal cells and are likely to be required for all membrane trafficking to the cell surface. Syntaxin1 mutations have pleiotropic non-neuronal phenotypes (Schulze et al., 1995), have defects in the cellularization of the syncytial blastoderm (Burgess et al., 1997), and appear to be cell-lethal (Schulze and Bellen, 1996; Burgess et al., 1997). Although embryonic synapses and axons form in syntaxin1 null mutations, the membrane addition for these processes is likely to be accomplished by syntaxin1 protein and message that are deposited by the mother in the egg (Parfitt et al., 1995; Burgess et al., 1997). Mutations of the n-sec-1 ho- 

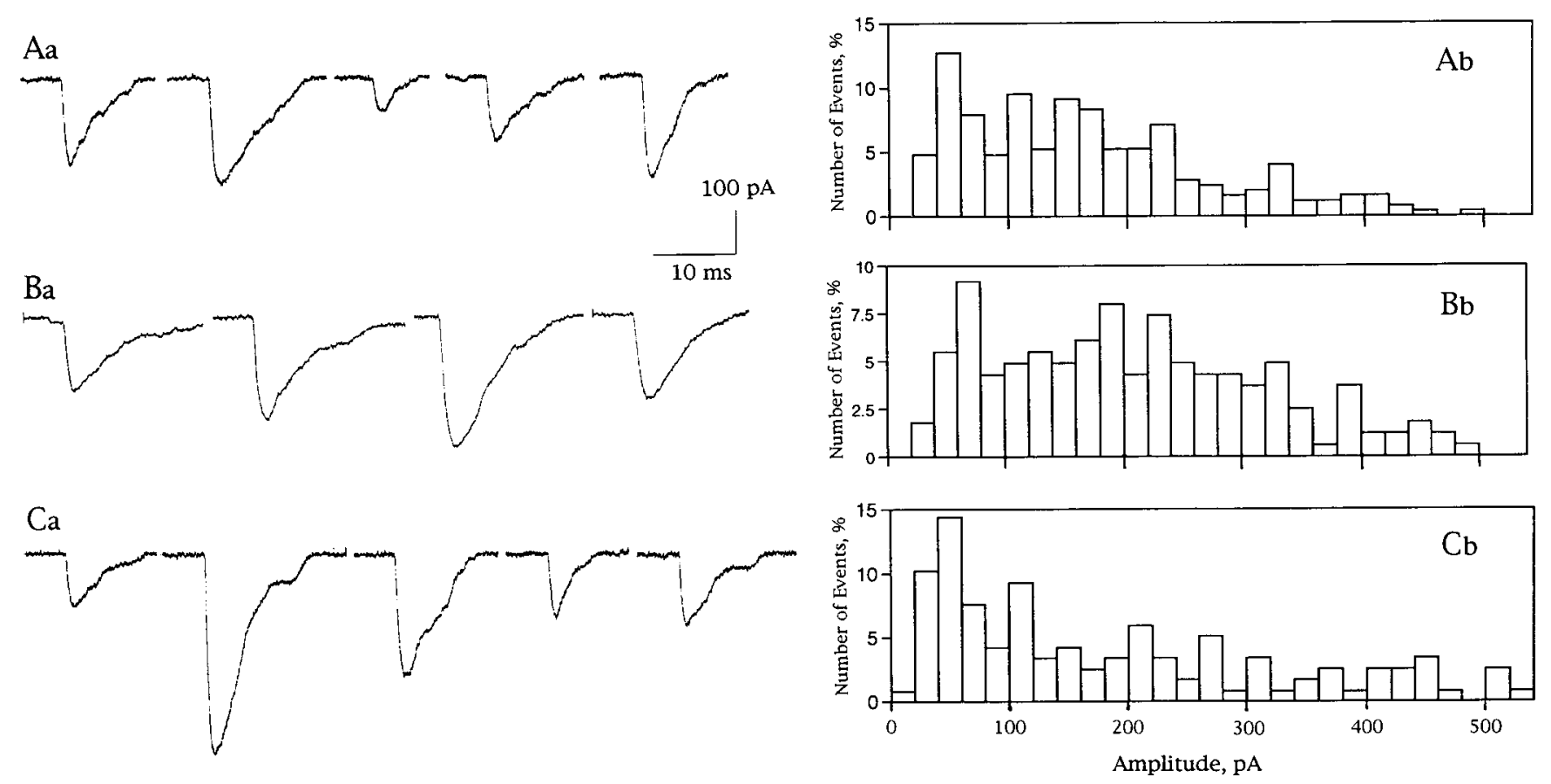

Figure 7. Representative miniature synaptic currents and amplitude histograms. Shown are miniature synaptic currents for $A a, n-s y b^{\Delta \mathrm{F} 33 \mathrm{~B}}$; $B a$, $n$-syb ${ }^{\mathrm{F} 33-\mathrm{R}}$; and $C a$, line 34 . Amplitude histogram for $A b$ is $n-s y b^{\Delta \mathrm{F} 33 \mathrm{~B}}$; for $B b$ is $n-s y b^{\mathrm{F} 33-\mathrm{R}}$; and for $C b$ is line 34 . Miniature synaptic currents were recorded in high $\mathrm{K}^{+}$saline $(20 \mathrm{mM})$ to increase their frequency and in the presence of $3 \mu \mathrm{M}$ TTX and $0.5 \mathrm{~mm} \mathrm{Ca}{ }^{2+}$. The mean amplitudes were $A$, $155 \pm$ $26 \mathrm{pA}(n=5) ; B, 199 \pm 16 \mathrm{pA}(n=7)$; and $C, 168 \pm 24 \mathrm{pA}(n=6)$, where $n$ is the number of cells.

molog rop also have pleiotropic effects in non-neuronal cells that suggest an essential role in all membrane addition to the cell surface (Harrison et al., 1994). In contrast, synaptotagmin mutations in the fly and nematode do not interfere with neurite and synapse formation and are not implicated in any defects outside the functioning of the mature synapse (DiAntonio et al., 1993b; Nonet et al., 1993).

Thus studies of other synaptic proteins provide a precedent for a single protein acting in multiple cellular processes: general membrane addition, axonal outgrowth, and exocytosis from the mature synapse. Other proteins, however, appear to be specific for synaptic vesicle fusion. In the present case the transcript pattern for $n-s y b$ pointed to a neuron-specific function for this protein (DiAntonio et al., 1993a), and the presence of normal axon tracts and synapses in the $n-s y b$ null mutants (see Fig. 4) indicates that it is essential only to the functioning of the synapse and not to its development.

\section{The discrimination of evoked responses from spontaneous miniature ESCs by mutations in $n$-syb}

The dramatic effect on evoked release and the more moderate effect on spontaneous release of the $n-s y b$ mutant are noteworthy for their implication that the mechanism of vesicle fusion for these two types of synaptic events may differ. At the NMJ, a 0.3 $\mathrm{Hz}$ stimulus to the motor nerve did not produce an ESC in these mutants. These findings are consistent with an essential role for $n-s y b$ in evoked neurotransmitter. On the other hand, the $n$-syb protein is not essential for spontaneous neurotransmitter release but does reduce the frequency of spontaneous mESCs significantly (by $75 \%$ in the $n$-syb null). Similar electrophysiological results were obtained by experiments in which the light chain of tetanus toxin was expressed in the Drosophila nervous system to reduce $n$-syb expression (Sweeney et al., 1995) and a smaller reduction in $\mathrm{mESC}$ frequency $(50 \%)$ was observed, although this difference was statistically insignificant. The key observation, however, that some mESCs persist in the absence of $n$-syb is confirmed by our study of a null allele.

Current models of VAMP/synaptobrevin function all invoke an action in concert with syntaxin and its cognate t-SNARE, and therefore it might be expected that the same phenotypes would arise if either member of the pair was disrupted. However, in Drosophila syntaxin1 mutants, both evoked release and spontaneous mESCs are disrupted (Schulze et al., 1995). Although rare spontaneous events were seen occasionally, these are likely to be mediated by residual maternal syntaxin1. Thus, as mentioned above, syntaxin1 appears to be required universally for fusion, whereas $n$-syb appears to be more specific.

The v-SNARE/t-SNARE model of VAMP/synaptobrevin function emphasizes a requirement for these proteins in targeting synaptic vesicles to active zones. However, EM data from tetanus toxin studies argue against this model. In both tetanus toxintreated squid giant synapses (Hunt et al., 1994) and Drosophila NMJ (Broadie et al., 1995), synaptic vesicles are still "docked" at active zones. Although we have not yet studied the $n$-syb mutants by electron microscopy, the persistence of spontaneous vesicle fusions in our genetic study would indicate that many vesicles are, indeed, docked at the plasma membrane. Thus it appears unlikely that the morphologically docked vesicles observed in the earlier studies were attributable to uncleaved synaptobrevin or residual function in the proteolyzed products. Our study and those with the toxin all point to a disruption of the evoked response that lies downstream of morphological vesicle docking. There may be several biochemical stages that intervene between docking and fusion (Banerjee et al., 1996), and $n$-syb may be necessary for one of these or for promoting fusion itself. 
The persistence of the spontaneous miniature EJCs in $n$-syb nulls raises two possibilities. The first is that the spontaneously fusing vesicles use an alternative isoform of synaptobrevin. Such an isoform, however, would not be redundant with $n$-syb; this homolog would be competent to mediate spontaneous fusions, but it would not be capable of responding to the $\mathrm{Ca}^{2+}$ signal that accompanies an action potential. One candidate is the other synaptobrevin isoform, $s y b$, the widespread distribution of which in the organism suggests a role in constitutive trafficking. However, we have observed very low levels of this protein in the synaptic regions of the nerve cord in wild-type embryos or in $n$-syb mutants (S. Bhattacharya, personal communication), and only low levels of $s y b \mathrm{mRNA}$ are found in the embryonic nervous system (Chin et al., 1993). syb is thus unlikely to be present on the majority of synaptic vesicles, although we cannot exclude that very low levels are present and suffice to produce the spontaneous events. In addition to $s y b$, an as yet unidentified member of the synaptobrevin family also may be present.

Alternatively, the mESCs may occur in the absence of any VAMP/synaptobrevin. Synaptic vesicles have been shown to contain a substantial amount of syntaxin and SNAP-25, and it is possible that these are adequate vesicular components to accomplish fusion. A recent study of the requirements of yeast endosomes to fuse with one another indicated that fusion was most efficient with both "v-SNARES" and "t-SNARES" present on both of the fusing organelles. Surprisingly, however, t-SNARE/ t-SNARE-mediated fusions (with a syntaxin homolog on both organelles, but no VAMP/synaptobrevin homolog on either) occurred at an appreciable rate that was approximately one-third as effective as having a v-SNARE on one side and a t-SNARE on the other (Nichols et al., 1997). With syntaxin1 (and SNAP-25) present on both vesicles and plasma membrane, our $n$-syb mutants may provide an in vivo correlate to the in vitro experiment with yeast endosomes.

\section{REFERENCES}

Ashton AC, Li Y, Doussau F, Weller U, Dougan G, Poulain B, Dolly JO (1995) Tetanus toxin inhibits neuroexocytosis even when its $\mathrm{Zn}^{2+}$. dependent protease activity is removed. J Biol Chem 270:31386-31390.

Banerjee, A, Barry V, DasGupta B, Martin T (1996) $N$-ethylmaleimidesensitive factor acts at a prefusion ATP-dependent step in $\mathrm{Ca}^{2+}$. activated exocytosis. J Biol Chem 271:20223-20226.

Bier E, Vaessin H, Shepherd S, Lee K, McCall K, Barbel S, Ackerman L, Carretto R, Uemura T, Grell E, Jan LY, Jan YN (1989) Searching for pattern and mutation in the Drosophila genome with a P-lacZ vector. Genes Dev 3:1273-1287.

Broadie K, Prokop A, Bellen H, O'Kane C, Schulze K, Sweeney S (1995) Syntaxin and synaptobrevin function downstream of vesicle docking in Drosophila. Neuron 15:663-673.

Burgess R, Deitcher D, Schwarz T (1997) The synaptic protein syntaxin1 is required for cellularization of Drosophila embryos. J Cell Biol 138:861-875.

Calakos N, Scheller RH (1996) Synaptic vesicle biogenesis, docking, and fusion: a molecular description. Physiol Rev 76:1-29.

Calakos N, Bennett MK, Peterson KE, Scheller RH (1994) Proteinprotein interactions contributing to the specificity of intracellular vesicular trafficking. Science 263:1146-1149.

Chin AC, Burgess RW, Wong BR, Schwarz TL, Scheller RH (1993) Differential expression of transcripts from $s y b$, a Drosophila melanogaster gene encoding VAMP (synaptobrevin) that is abundant in nonneuronal cells. Gene 131:175-181.

Church G, Gilbert W (1984) Genomic sequencing. Proc Natl Acad Sci USA 81:1991-1995.
DiAntonio A, Burgess RW, Chin AC, Deitcher DL, Scheller RH, Schwarz TL (1993a) Identification and characterization of Drosophila genes for synaptic vesicle proteins. J Neurosci 13:4924-4935.

DiAntonio A, Parfitt K, Schwarz T (1993b) Synaptic transmission persists in synaptotagmin mutants of Drosophila. Cell 73:1281-1290.

Foran P, Lawrence GW, Shone CC, Foster KA, Dolly JO (1996) Botulinum neurotoxin $\mathrm{C} 1$ cleaves both syntaxin and SNAP-25 in intact and permeabilized chromaffin cells: correlation with its blockade of catecholamine release. Biochemistry 35:2630-2636.

Gho M (1994) Voltage-clamp analysis of gap junction between embryonic muscles in Drosophila. J Physiol (Lond) 481:371-383.

Gonczy P, Viswanathan S, DiNardo S (1992) Probing spermatogenesis in Drosophila with P-element enhancer detectors. Development 114:89-98.

Harlow E, Lane D (1988) Antibodies: a laboratory manual. Cold Spring Harbor, NY: Cold Spring Harbor Laboratory.

Harrison SD, Broadie K, van de Goor J, Rubin G (1994) Mutations in the Drosophila rop gene suggest a function in general secretion and synaptic transmission. Neuron 13:555-566.

Hunt J, Bommert K, Charleton M, Kistner A, Habermann E, Augustine G, Betz H (1994) A post-docking role for synaptobrevin in synaptic vesicle fusion. Neuron 12:1269-1279.

Igarashi M, Kozaki S, Terakawa S, Kawano S, Ide C, Komiya Y (1996) Growth cone collapse and inhibition of neurite growth by botulinum neurotoxin C1: a t-SNARE is involved in axonal growth. J Cell Biol 134:205-215.

Jahn R, Südhof TC (1994) Synaptic vesicles and exocytosis. Annu Rev Neurosci 17:219-246.

Jan YN, Jan LY (1977) Two mutations of synaptic transmission in Drosophila. Proc R Soc Lond [Biol] 198:87-108.

Kaiser K, Goodwin S (1990) "Site-selected" transposon mutagenesis of Drosophila. Proc Natl Acad Sci USA 87:1686-1690.

Kidokoro Y, Nishikawa K (1994) Miniature endplate currents at the newly formed neuromuscular junction in Drosophila embryos and larvae. Neurosci Res 19:143-154.

Mi H, Deerinck T, Ellisman M, Schwarz T (1995) Differential distribution of closely related potassium channels in rat Schwann cells. J Neurosci 15:3761-3774.

Nichols B, Ungerman U, Pelham H, Wickner W, Hass A (1997) Homotypic vacuolar fusion mediated by $t-$ and v-SNAREs. Nature 387:199-202.

Nishikawa K, Kidokoro Y (1995) Junctional and extrajunctional glutamate receptor channels in Drosophila embryos and larvae. J Neurosci 15:7905-7915.

Nonet M, Grundahl K, Meyer B, Rand J (1993) Synaptic function is impaired but not eliminated in Caenorhabditis elegans mutants lacking synaptotagmin. Cell 73:1291-1305.

Osen-Sand A, Catsicas M, Staple J, Jones K, Ayala G, Knowles J, Grenningloh G, Catsicas S (1993) Inhibition of axonal growth by SNAP-25 antisense oligonucleotides in vitro and in vivo. Nature 364:445-448.

Parfitt K, Reist N, Li J, Burgess R, Deitcher D, DiAntonio A, Schwarz TL (1995) Drosophila genetics and the functions of synaptic proteins. Cold Spring Harb Symp Quant Biol 60:371-377.

Schiavo G, Benfenati F, Poulain B, Rosetto O, de Laureto P, DasGupta B, Montecucco C (1992) Tetanus and botulinum-B neurotoxins block neurotransmitter release by proteolytic cleavage of synaptobrevin. Nature 359:832-835.

Schiavo G, Malizio C, Trimble W, De Laureto P, Milan G, Sugiyama H, Johnson E, Montecucco C (1994a) Botulinum-G neurotoxin cleaves VAMP-synaptobrevin at a single ala-ala peptide bond. J Biol Chem 269:20213-20216.

Schiavo G, Rosetto O, Benfenati F, Poulain B, Montecucco C (1994b) Tetanus and botulinum neurotoxins are zinc proteases specific for components of the neuroexocytosis apparatus. Ann NY Acad Sci 719:65-75.

Schulze KL, Bellen HJ (1996) Drosophila syntaxin is required for cell viability and may function in membrane formation and stabilization. Genetics 144:1713-1724.

Schulze KL, Broadie K, Perin M, Bellen HJ (1995) Genetic and electrophysiological studies of Drosophila syntaxin-1A demonstrate its role in nonneuronal secretion and neurotransmission. Cell 80:311-320.

Söllner T, Bennet MK, Whiteheart SW, Scheller RH, Rothman JE (1993) A protein assembly-disassembly pathway in vitro that may 
correspond to sequential steps of vesicle docking, activation, and fusion. Cell 75:409-418.

Stewart B, Atwood H, Renger J, Wang J, Wu C (1994) Improved stability of Drosophila larval neuromuscular preparations in haemolymphlike physiological solutions. J Comp Physiol [A] 175:179-191.

Südhof TC, Baumert M, Perin MS, Jahn R (1989) A synaptic vesicle membrane protein is conserved from mammals to Drosophila. Neuron 2:1475-1481.

Sweeney ST, Broadie K, Keane J, Niemann H, O'Kane CJ (1995) Targeted expression of tetanus toxin light chain in Drosophila specifically eliminates synaptic transmission and causes behavioral defects. Neuron 14:341-351.

Tower J, Karpen G, Craig N, Spradling A (1993) Preferential transposi- tion of Drosophila P-elements to nearby chromosomal sites. Genetics 133:347-359.

Ueda A, Kidokoro Y (1996) Longitudinal body wall muscles are electrically coupled across the segmental boundary in the third instar larva of Drosophila melanogaster. Invert Neurosci 1:315-322.

Yamasaki S, Baumeister A, Binz T, Blasi J, Link E, Cornille F, Roques B, Fykes E, Südhof T, Jahn R, Niemann H (1994) Cleavage of members of the synaptobrevin/VAMP family by types D and $\mathrm{F}$ botulinal neurotoxins and tetanus toxin. J Biol Chem 269:12764-12772.

Zinsmaier K, Eberle K, Buchner E, Walter N, Benzer S (1994) Paralysis and early death in cysteine string protein mutants of Drosophila. Science 263:977-980. 